\title{
Long isoform of prolactin receptor predominates in rat intrahepatic bile ducts and further increases under obstructive cholestasis
}

\author{
R L Bogorad, T Y Ostroukhova, A N Orlova, P M Rubtsov ${ }^{1}$ \\ and $\mathbf{O} \mathbf{V}$ Smirnova \\ Laboratory of Endocrinology, Faculty of Biology, Lomonosov Moscow State University, Vorob'ev Hills, 119992, Moscow, Russian Federation \\ ${ }^{1}$ Laboratory of Hormones and Receptors, Engelhardt Institute of Molecular Biology, Russian Academy of Sciences, 32 Vavilova Str., 119991, Moscow, \\ Russian Federation \\ (Requests for offprints should be addressed to R L Bogorad; Email: rbogorad@yahoo.com)
}

\begin{abstract}
Prolactin participates in the regulation of liver function. However, prolactin receptor (PrlR) expression and its regulation have been described only for hepatocytes. In this study, we investigated the expression and regulation of PrlR isoforms in the other important intrahepatic cellular compartment: the biliary epithelial cells, or cholangiocytes. Our aim was to determine whether prolactin should be considered as a potential regulator of cholangiocyte function under normal and pathological conditions. Cholangiocytes and hepatocytes were differentially isolated from rat liver. PrlR expression was analysed at the mRNA level by isoform-specific semiquantitative PCR, and at the protein level by immunostaining of liver sections. Hormonal regulation of PrlR expression was evaluated by comparing intact rats with gonadectomized, pituitary-grafted or
\end{abstract}

bromocriptine-treated animals. Common bile-duct ligation was used as the experimental model of cholestasis. Our results demonstrate that the expression pattern and regulation of $\operatorname{PrlR}$ isoforms is totally different in cholangiocytes compared with hepatocytes: (1) mature rat cholangiocytes express low levels of PrlR, while it is very high in hepatocytes, (2) only the long isoform is detected in cholangiocytes, while the short isoform predominates in hepatocytes and (3) PrlR levels in cholangiocytes are induced by obstructive cholestasis, but not by sex hormones or prolactin, while it is the opposite in hepatocytes. From these data, the actions of prolactin on liver are anticipated to exhibit strong cell-type specificity in both normal and pathological conditions.

Journal of Endocrinology (2006) 188, 345-354

\section{Introduction}

Several prolactin receptor (PrlR) isoforms have been identified in mammals. In rat, they have been shown to be produced via alternative splicing of PrlR pre-mRNA: the formation of long and short isoforms result from alternative inclusion of proximal exon 10 or distal exon 11 into the mature mRNA, respectively (Bole-Feysot et al. 1998). These receptor isoforms differ in length and structure of their intracellular domain, which affects signalling properties. Thus, tissue sensitivity and responsiveness to prolactin depend on both the level of total PrlR expression and the ratio of short to long isoforms.

Prolactin signalling is initiated by formation of a complex involving one prolactin molecule and two molecules of PrlR. The long PrlR isoform activates various signalling cascades, among which Janus kinase/signal transduction and activators of transcription (JAK/STAT) is considered to be the central pathway (Bole-Feysot et al. 1998). The short PrlR isoform exerts dominant-negative effects on
STAT activation, resulting from formation of short and long PrlR heterodimers (Perrot-Applanat et al. 1997). However, short PrlR is also involved in transduction of specific signals, including activation of serine/threonine protein kinase cascades and interaction with 17-hydroxysteroid dehydrogenase (Das \& Vonderhaar 1995, Duan et al. 1997, Nikelainen et al. 1998).

Liver is very specific compared with other organs with respect to PrlR expression: the level of PrlR is higher than in most other tissues, and this mainly involves the short isoform since the long PrlR is 10\% of total (Nagano \& Kelly 1994). The total level of PrlR in hepatocytes is regulated by sex hormones: oestrogens increase and androgens decrease the content of PrlR mRNA and protein (Jolicoeur et al. 1989, Sakaguchi et al. 1994). As in other tissues, prolactin was shown to be another positive regulator of PrlR expression in the liver (Baxter \& Zaltsman 1984, Bogorad et al. 2000). Although PrlR expression is well documented, the actions of prolactin in liver remain poorly understood (Bole-Feysot et al. 1998). 
Relatively few disembodied data were published regarding prolactin effects on hepatocyte proliferation (Picolleti et al. 1997) as well as on expression of a number of hepatocyte proteins (Bole-Feysot et al. 1998, Liu et al. 1992). No liver phenotype has been reported in prolactinor PrlR-knockout mice (Horseman et al. 1997, Ormandy et al. 1997), which does not exclude compensatory actions by other cytokine receptors.

Although liver consists essentially of hepatocytes, another important cell compartment involves intrahepatic biliary epithelial cells, referred to as cholangiocytes. These cells are organized in a three-dimensional network of ducts, which implies interactions with other hepatic cell types. Despite their relatively small number, cholangiocytes play an essential role in liver functions, including bile formation and secretion (Alpini et al. 1994b). The proportion and activity of these two cell types can change dramatically depending on the conditions. During hepatic diseases, such as obstructive cholestasis or jaundice, the bile tree grows intensively, and the proportion of cholangiocytes can be increased to up to $20 \%$ of total liver cells (Alpini et al. 1994a). The responsiveness of cholangiocytes to various regulatory factors is also markedly enhanced under cholestatic conditions (Alpini et al. 1994b, Alvaro et al. 2000b). Because prolactin participates in the regulation of water-ion balance and secretory processes (Bole-Feysot et al. 1998), its involvement in the regulation of cholangiocyte function is expected. However, since evidence is still lacking that these cells express PrlR, any effect of prolactin under normal or pathological states remains speculative. These issues were addressed in our study. We report the profile of expression on both long and short PrlR isoforms in rat liver, under normal and cholestatic conditions. We also provide some clues on their regulation by sex hormones and prolactin. The unexpected conclusion of our investigations is that the expression of PrlR isoforms and their regulation in cholangiocytes and hepatocytes are dramatically different, and in many cases opposite.

\section{Materials and Methods}

\section{Animals}

All animals were housed on standard rodent chow and tap water ad libitum and received humane care, the study protocols complied with the Faculty of Biology's (Lomonosov Moscow State University) guidelines.

Intact mature 12-week-old male and female rats as well as immature rats were used to determine the parameters of PrlR expression. To study the influence of sex hormones sexually mature animals were gonadectomized (Smirnova et al. 1998) and rested for 30 days.

For experimental stimulation of bile-duct cell proliferation, intact and gonadectomized animals underwent common bile-duct ligation (CBDL) for 14 days, according to Alpini et al. (1989). In order to elevate the circulating prolactin level some rats were subjected to transplantation of two donor pituitaries into kidney capsule. The completeness of graft acceptance was determined for each animal by autopsy. This well-characterized impact increases the prolactin level approximately 5 -fold, to $55 \mathrm{ng} / \mathrm{ml}$ (Garcia et al. 2003). In 2 days recipient animals underwent CBDL.

Bromocriptine was injected daily after CBDL as 50\% ethanol suspension of bromocriptine pills (Gedeon Richter, Budapest, Hungary; $10 \mu \mathrm{g} / \mathrm{kg}$ animal weight) to decrease the level of circulating prolactin. Vehicle was injected into control animals. This treatment decreases the prolactin level $10-$ fold, to approximately $1 \mathrm{ng} / \mathrm{ml}$ (Bogorad et al. 2000).

The tissues were subjected to simultaneous isolation of bile-duct units and hepatocytes or fixed in 4\% paraform and used for immunohistochemical staining.

All animal groups were compared with the corresponding sham-operated group to control for non-specific effects. The preliminary reverse transcriptase (RT)-PCR experiments did not reveal any influence of sham operations on PrlR mRNA level or ratio of PrlR isoforms in cholangiocytes (one-way analysis of variance (ANOVA), $P>0 \cdot 6$; data not shown).

\section{Immunohistochemistry and cytophotometry}

Tissues were embedded in paraplast and sliced into $3 \mu \mathrm{m}$ sections. Immunohistochemical staining of sections with anti-PrlR antibodies (clone U5; provided by Dr V Goffin and Dr P Kelly, INSERM, Paris, France) and cytophotometry were done as described previously (Bogorad et al. 2000). One hundred and fifty cells on two tissue sections of each animal were measured for the intensity of PrlR-positive immunostaining, which is represented as optical density (OD).

\section{Simultaneous isolation of bile-duct units and hepatocytes}

In some experiments, the rat livers were subjected to isolation of hepatocytes and cholangiocytes as intrahepatic bile-duct units (Mennone et al. 1995). Briefly, the liver was perfused by $\mathrm{Ca}^{2+}-/ \mathrm{Mg}^{2+}$-free Hanks' balanced salts solution (all reagents and enzymes for cell isolation and reagents for tissues preparations were from Sigma) containing $0.7 \mathrm{mM}$ EDTA, then perfused through the portal vein by collagenase (0.05\%) in Hanks' balanced salts solution with $40 \mathrm{mM}$ HEPES and $5 \mathrm{mM} \mathrm{CaCl}_{2}$. Residual portal tissue was mechanically dissociated from hepatocytes and then minced and incubated at $37^{\circ} \mathrm{C}$ with solution A ( $\alpha$-MEM containing $0.05 \%$ collagenase, $0.006 \%$ DNase and $0.033 \%$ pronase) and solution B $(\alpha$-MEM containing the same enzymes except for pronase which was replaced with $0.036 \%$ hyaluronidase). The obtained suspension was subsequently filtered through 


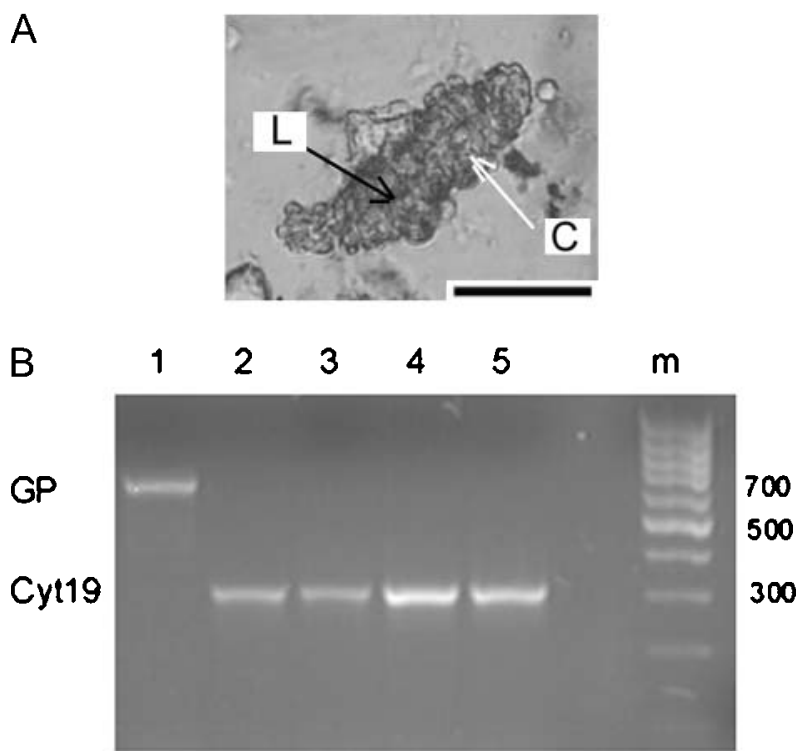

Figure 1 Differential isolation of bile-duct units. (A) Isolated bile-duct units (tubule-like structures), non-fixed and non-stained. $\mathrm{L}$, lumen; C, cholangiocyte. Scale bar, $25 \mu \mathrm{m}$. (B) PCR control of rat cholangiocyte purity. Lanes: 1 , hepatocytes isolated from liver of mature female rat; $2-5$ bile-duct units isolated from liver of: 2 , intact mature female rat; 3 , intact mature male rat; 4 , mature female rat with $\mathrm{CBDL}$; 5 , mature male rat with $\mathrm{CBDL}$. m, DNA size markers (bp); GP, glucose-6-phosphatase (specific marker of hepatocytes); Cyt19, cytokeratin 19 (specific marker of bile-duct epithelial cells).

100 and $30 \mu \mathrm{m}$ nylon net filters (Millipore, Billerica, MA, USA), and bile-duct units that remained on $30 \mu \mathrm{m}$ mesh were collected and checked by light microscopy for morphology and purity (Fig. 1A). Additional confirmation of purity of isolated cholangiocytes was provided by RT-PCR with primers for mRNA of bile-duct epithelial cell marker cytokeratin 19 and hepatocyte marker

Table 1 Oligonucleotide primers used in PCR analysis

\begin{tabular}{|c|c|c|c|}
\hline & Primer & Nucleotide sequence & Product length $(b p)$ \\
\hline \multicolumn{4}{|l|}{ cDNA (GenBank accession number) } \\
\hline \multirow[t]{2}{*}{ Prolactin receptor common fragment (M57668) } & $\mathrm{Rf}$ & f 5'-gtagatggagccaggagagttc-3' & 163 \\
\hline & Rc & r 5'-ggtggaaagatgcaggtcatcat-3' & \\
\hline \multirow[t]{2}{*}{ Prolactin receptor long isoform (M57668) } & $\mathrm{Rf}$ & f $5^{\prime}$-gtagatggagccaggagagttc-3' & 404 \\
\hline & $\mathrm{RI}$ & r 5'-accagagtcactgtcgggatct-3' & \\
\hline \multirow{2}{*}{ Prolactin receptor short isoform (M19304) } & $\mathrm{Rf}$ & f $5^{\prime}$-gtagatggagccaggagagttc- $3^{\prime}$ & 315 \\
\hline & Rs & r 5'-tgagtctgcagcttcagtagtca-3' & \\
\hline \multirow[t]{2}{*}{ B-Actin (NM_031144) } & Baf & f $5^{\prime}$-atctggcaccacaccttctacaatgagc- $3^{\prime}$ & 829 \\
\hline & Bar & r $5^{\prime}$-actcctgcttgctgatccacatctgc-3' & \\
\hline \multirow[t]{2}{*}{ Cytokeratin-19 (X81449) } & Cytf & f $5^{\prime}$-tgcgcgacaacatccttggc- $3^{\prime}$ & 310 \\
\hline & Cytr & r 5'-gtggaatccacctccacact-3' & \\
\hline \multirow[t]{2}{*}{ Glucose-6-phosphastase (NM_013098) } & GPf & f $5^{\prime}$-caagagactgtgggcatcaatc- $3^{\prime}$ & 621 \\
\hline & GPr & r 5'-gctggcaaagggtgtagtgt-3' & \\
\hline \multirow[t]{2}{*}{ Prolactin (NM_012629) } & Prf & f $5^{\prime}$-ctggtggcgactgccagacacct-3' & 374 \\
\hline & Prr & r 5'-ttcaatcccttcaagaagccg-3' & \\
\hline
\end{tabular}

Oligonucleotides were purchased from Syntol, Moscow, Russia. f, forward-strand primer; r, reverse-strand primer. glucose-6-phosphatase (Alpini et al. 1994a; Fig. 1B). Viability of the bile-duct units was $>95 \%$ as assessed by Trypan Blue exclusion immediately after cell isolation.

\section{RNA isolation and $c D N A$ synthesis}

A total RNA was immediately extracted from hepatocytes and bile-duct fragments according to Chomczynski \& Sacchi (1987). The total RNA concentration was assessed needed. The RNA integrity and purity were verified by agarose gel electrophoresis and spectrophotometry.

Equal quantities of total RNA $(0.47 \mu \mathrm{g})$ from each sample were reverse-transcribed into cDNA with the Superscript II RT kit (Invitrogen) using 1.5 $\mu$ g oligo-dT $_{15}$ (Syntol, Moscow, Russia). The reaction was performed in $57 \mu \mathrm{l}$ for $1 \mathrm{~h}$ at $42{ }^{\circ} \mathrm{C}$ with 600 units RT. RNA incubated under identical conditions, but without reverse transcriptase served as a negative control.

\section{PCR}

PCR was performed in a volume of $25 \mu \mathrm{l}$ containing $1 \times$ Taq DNA polymerase buffer, consisting of $100 \mu \mathrm{M}$ dNTP (MBI Fermentas, Vilnius, Lithuania), 0.5 units Taq polymerase (Dialat, Moscow, Russia) and $2 \mu \mathrm{l}$ RT reaction aliquot. Probes contained $25 \mathrm{pmol}$ of each required oligonucleotide. The GenBank accession numbers of the cDNAs and the size of amplified fragments are listed in Table 1. PCRs were performed usually for 33 cycles (unless otherwise indicated) with the following regimen: $30 \mathrm{~s}$ at $94{ }^{\circ} \mathrm{C}, 30 \mathrm{~s}$ at $60{ }^{\circ} \mathrm{C}$ and $45 \mathrm{~s}$ at $72{ }^{\circ} \mathrm{C}$.

To check possible reciprocal contamination of cell preparations, PCR was performed for the cDNA of a cholangiocyte marker (cytokeratin 19) using Cytf and Cytr primers and for the cDNA of a hepatocyte marker by $A_{260}$ and isolated RNA was stored at $-50{ }^{\circ} \mathrm{C}$ until 
A

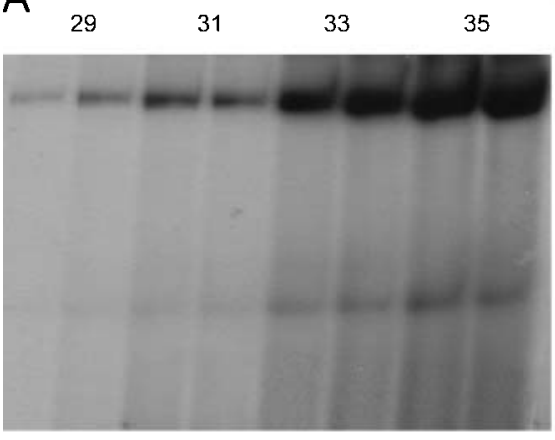

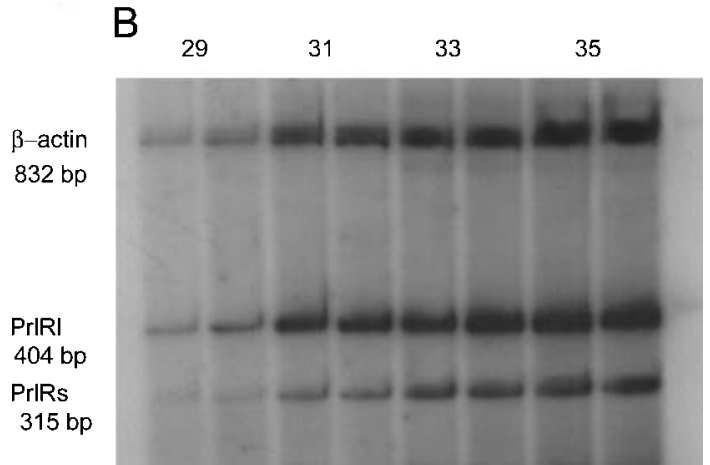

Figure 2 Semiquantitative assay of mRNA of short and long PrIR isoforms by RT-PCR. Autoradiographs of PCR products of $\beta$-actin, PrIR long (PrIRI) and PrIR short (PrIRs) mRNA isoforms separated in 5\% polyacrylamide gel. (A) Cholangiocytes of normal rat; (B), cholangiocytes of rat under obstructive cholestasis. The numbers of PCR cycles are given at the top. Positions and lengths of amplification products for cDNAs of $\beta$-actin and short and long isoforms of PrlR are shown. The quantification of PrIR mRNA levels of all experimental groups is presented in Table 2.

(glucose-6-phospatase) using GPf and GPr primers (Table 1). For detection of prolactin cDNA 40 cycles of PCR were done with Prf and Prr primers. The PCR products were resolved in $1.5 \%$ agarose gel containing ethidium bromide (Sigma). The GeneRuler 100 bp DNA ladder (MBI Fermentas) was used for sizing of DNA fragments.

\section{Semiquantitative $R T-P C R$ assay of $\operatorname{Prl} R \mathrm{mRN} A$ and isoform ratio}

The first step in the validation of semiquantitative RTPCR for PrlR mRNA reactions were performed under similar conditions with the primers $\mathrm{Rf}, \mathrm{Rl}$ and $\mathrm{Rs}$ to amplify the fragments of long and short mRNAs of PrlR. The PCR products were separated in agarose gel and transferred onto Hybond-N according to standard procedure. The membranes were incubated with $\gamma-{ }^{32} \mathrm{P}-$ labelled Rc primer. The length of amplified fragments of PrlR cDNAs corresponded to expected values: $404 \mathrm{bp}$ for the long form and $315 \mathrm{bp}$ for the short one. Products of other sizes were not detected by staining of agarose gel with ethidium bromide or by hybridization with $\gamma-{ }^{32}$ P-labelled Rc, homologous for cDNA of both PrlR isoforms (data not shown). The identity of the nucleotide sequences of amplified fragments to respective segments of cDNA of short and long PrlR forms was confirmed by sequencing of obtained PCR products.

Further semiquantitative PCR for PrlR was performed in the following conditions: each probe contained primers Baf, Bar, Rf and Rc (to assay the total PrlR level) or Baf, Bar, Rf, Rs and Rl (to estimate the ratio of PrlR isoforms); $\beta$-actin served as an internal standard in both cases. Rf and Baf (1 pmol), labelled by polynucleotide kinase in the presence of $\left[\gamma-{ }^{32} \mathrm{P}\right] \mathrm{ATP}$, were added to each probe. The preliminary results demonstrated the exponential phase of amplification of transcripts of $\beta$-actin and both PrlR isoforms from the 25th to the 33rd cycles (Bogorad et al. 2002, 2004). For competitive kinetic analysis, all reactions were run in duplicate. The PCR products were separated by polyacrylamide gel electrophoresis (Fig. 2) and quantified by measuring radioactivity of incorporated isotopes. The region of reliable detection of PCR products and linearity of radioactivity logarithm was from the 29th to the 33rd cycle of amplification (Bogorad et al. 2004). Relative levels of PrlR mRNA were expressed as arbitrary units (a.u.) after normalization to $\beta$-actin mRNA levels. The PrlR level for each animal was determined based on at least two independent RT reactions. A detectable level of PrlR mRNA was reproducibly estimated at $0 \cdot 01$ a.u.

\section{Statistical analysis}

Values for cytophotometry (five or six animals in each group) and RT-PCR results of PrlR level (four or five animals in each group) are represented as means \pm S.D. Statistical significance was assessed by one-way ANOVA for multiple comparison followed by Mann-Whitney $U$-test; $P<0 \cdot 05$ was considered significant.

\section{Results}

Parameters of PrlR expression in the cholangiocytes of normal male and female rats

Hepatocytes of female rats are known to express almost the highest level of PrlR of all tissues. Our data obtained by immunostaining confirm this fact as well as an obvious dependence of PrlR immunostaining in hepatocytes on gender (Fig. 3A and B), which is also well established 

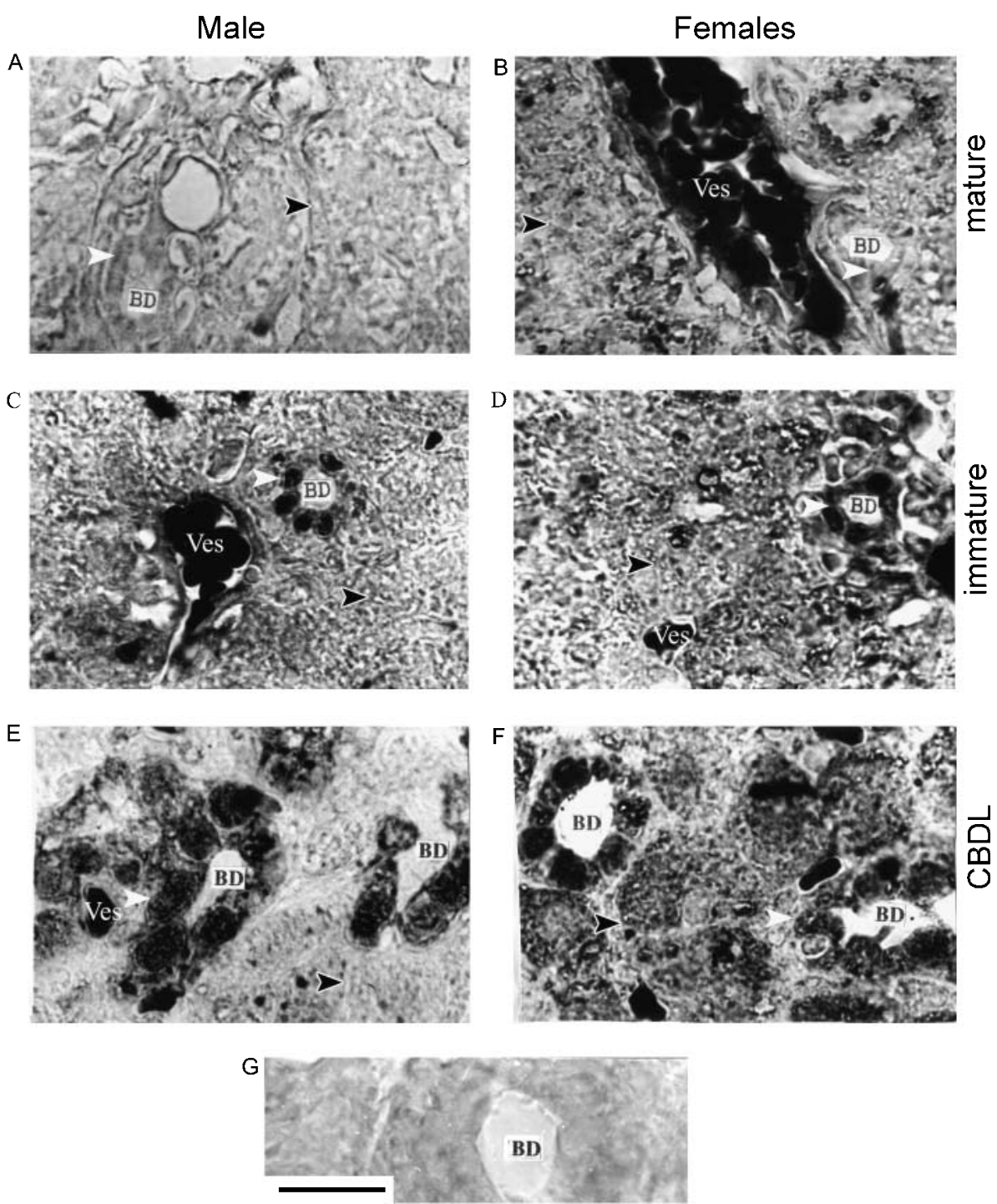

Figure 3 Immunocytochemical identification of PrIR in liver tissue of different experimental groups. $\mathrm{BD}$, bile ducts; scale bar, $25 \mu \mathrm{m}$. White arrowheads, bile ducts (cholangiocytes); black arrowheads, hepatocytes; Ves, vessels (erythrocytes are strongly stained due to false-positive peroxidase reaction not inhibited by sodium periodate treatment). (A, B) Mature rats; $(C, D)$, immature rats; ( $E$, F), mature rats after 14 days $\mathrm{CBDL}(\mathrm{G})$ negative control for immunohistochemical staining of prolactin receptor; anti-PrIR antibodies were omitted.

(Sakaguchi et al. 1994, Smirnova et al. 1994, Bogorad et al. 2004): male sex hormones decrease and female sex hormones increase PrlR level. In contrast, immunohistochemistry did not reveal any pronounced PrlR-positive signal in cholangiocytes (Fig. $3 \mathrm{~A}$ and $\mathrm{B}$ ). However, we succeeded in detecting of PrlR mRNA in cholangiocytes of intact animals of both sexes by RT-PCR (Fig. 2A). This level was found to be low and surprisingly sex-independent.

To compare the influence of sex hormones on PrlR mRNA levels in rat cholangiocytes and hepatocytes we tested the effect of gonadectomy on PrlR level. We did not find any changes in PrlR mRNA level in bile-duct epithelial cells (Fig. 4A), in contrast to hepatocytes (Fig. 4B). It is noteworthy that PrlR mRNA levels in cholangiocytes and hepatocytes are well correlated with $\mathrm{PrlR}$-positive immunostaining of liver tissue sections (Fig. 3A and B).

To investigate the proportion of PrlR isoforms in both cell types, we performed semiquantitative PCRs specific for long and short isoforms. Our results confirm that hepatocytes express predominantly the short isoform of PrlR (Nagano \& Kelly 1994). Surprisingly, the long 

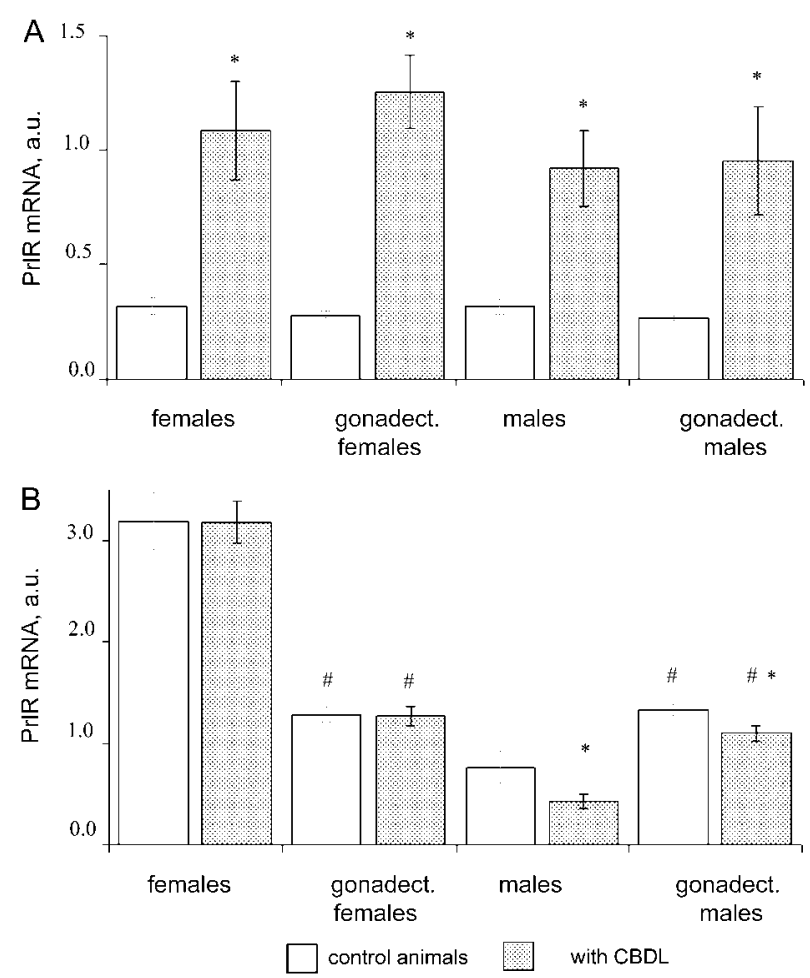

Figure 4 Influence of obstructive cholestasis on the level of mRNA of PrlRs in mature rat cholangiocytes (A) and hepatocytes (B). PrIR level was measured by RT-PCR (primers for the common fragment of PrIR). a.u., arbitrary units as the ratio of PrIR mRNA to mRNA of $\beta$-actin. White bars, control animals; black bars, rats after 14 days CBDL. ${ }^{*} P<0 \cdot 05$, rats with $\mathrm{CBDL}$ versus control rats; $\# P<0 \cdot 05$, rats with gonadectomy versus control rats.

PrlR isoform was revealed to be the only isoform in cholangiocytes of mature intact rats of both sexes (Table 2). The short isoform was not detected in these cells even by one-side nested PCR (25 cycles with primers specific for short isoform followed by 25 cycles with primers specific for the common fragment of PrlR (see Table 1); data not shown).
Moreover, we have previously shown (Bogorad et al. 2004) that the ratio of the short to long isoform in hepatocytes is regulated by sex hormones: both male and female sex hormones increase the ratio of the short to long mRNA isoform of PrlR (Table 3). In contrast, the pattern of PrlR isoforms mRNA in cholangiocytes remains unchanged after gonadectomy (Table 2).

While in mature rats PrlR-positive immunostaining of cholangiocytes was very low, cholangiocytes at the earlier stages of postnatal development (45th day post partum) were characterized by transient, sex-independent elevation of PrlR-positive staining, which was much more intense then in hepatocytes at the same stage (Fig. 3C and D). This increased PrlR level is associated with intensive proliferation of bile-duct epithelium, shown earlier by Alpini et al. (1988).

\section{The pattern of PrlR expression in proliferating cholangiocytes} under $C B D L$

To investigate whether PrlR expression in cholangiocytes is correlated with their activated function and/or proliferation, we have used a well-established model for inducing bile-duct cell proliferation (Alpini et al. 1994): CBDL is an experimental model of different pathological conditions such as obstructive cholestasis and jaundice. CBDL promoted PrlR immunostaining in cholangiocytes of both male and female rats (Fig. 3E and F). PrlR staining was localized in the perinuclear space of proliferating cholangiocytes (nuclei of bile-duct epithelial cells under these conditions constitute approximately $60-70 \%$ of the cell surface). We confirmed PrlR upregulation by semiquantitative RT-PCR assay: CBDL was shown to lead to a 3.0-3·4-fold increase in PrlR mRNA level in cholangiocytes of both male and female rats (Fig. 4A). In sharp contrast, CBDL did not induce an increase of either PrlR-positive immunostaining (Fig. 3C and D) or mRNA level (Fig. 4B) in hepatocytes of mature rats. Moreover, in the hepatocytes of male rats, the level of PrlR mRNA was shown to have slightly decreased.

Table 2 The relative levels of PrIR mRNA isoforms in rat cholangiocytes of different experimental groups

Relative levels of PrIR mRNA (a.u. \pm s.D.)

\begin{tabular}{|c|c|c|c|c|c|c|}
\hline & \\
\hline & \multicolumn{3}{|l|}{ Control groups } & \multicolumn{3}{|c|}{ Groups with CBDL } \\
\hline Gonadectomized females & ND & $0 \cdot 08 \pm 0.04$ & $<0 \cdot 1$ & $0.11 \pm 0.03^{*}$ & $0 \cdot 30 \pm 0 \cdot 04^{*}$ & $0 \cdot 36$ \\
\hline Males & ND & $0 \cdot 11 \pm 0 \cdot 01$ & $<0 \cdot 1$ & $0 \cdot 11 \pm 0 \cdot 01^{*}$ & $0 \cdot 24 \pm 0 \cdot 07^{*}$ & $0 \cdot 45$ \\
\hline Gonadectomized males & ND & $0.09 \pm 0.03$ & $<0 \cdot 1$ & $0 \cdot 10 \pm 0 \cdot 04^{*}$ & $0 \cdot 21 \pm 0 \cdot 04^{*}$ & $0 \cdot 48$ \\
\hline
\end{tabular}

\footnotetext{
${ }^{1}$ Ratio of prolactin receptor short to long mRNA isoforms.

${ }^{2}$ mRNA of short PrIR is not detectable and its level is considered to be below the sensitivity of applied PCR method (0.01 a.u.).

${ }^{3}$ The $S / L$ ratio for control animals was estimated based on the sensitivity of the method $(0 \cdot 01$ a.u. $)$.

${ }^{*} P<0 \cdot 05$, cholangiocytes of rats with CBDL versus rats without CBDL.
} 
Table 3 The relative levels of PrIR mRNA isoforms in rat hepatocytes of different experimental groups

Relative levels of PrIR mRNA (a.u. \pm s.D.)

\begin{tabular}{|c|c|c|c|c|c|c|}
\hline & \\
\hline & \multicolumn{3}{|l|}{ Control groups } & \multicolumn{3}{|c|}{ Groups with CBDL } \\
\hline & Short isoform & Long isoform & $\mathrm{S} / \mathrm{L} \mathrm{ratio}^{1}$ & Short isoform & Long isoform & $\mathrm{S} / \mathrm{L}$ ratio \\
\hline \multicolumn{7}{|l|}{ Groups } \\
\hline Females & $1 \cdot 30 \pm 0 \cdot 22$ & $0 \cdot 13 \pm 0 \cdot 01$ & $10 \cdot 00$ & $0 \cdot 87 \pm 0 \cdot 02^{*}$ & $0 \cdot 56 \pm 0 \cdot 12^{\star}$ & $1 \cdot 55$ \\
\hline Gonadectomized females & $0.42 \pm 0.04 \dagger$ & $0 \cdot 15 \pm 0 \cdot 02$ & $2 \cdot 80$ & $0 \cdot 33 \pm 0 \cdot 03^{*}$ & $0 \cdot 24 \pm 0 \cdot 02^{*}$ & $1 \cdot 38$ \\
\hline Males & $0 \cdot 27 \pm 0 \cdot 06 \neq$ & $0.07 \pm 0.02 \ddagger$ & $3 \cdot 86$ & $0.12 \pm 0.02^{*}$ & $0 \cdot 07 \pm 0 \cdot 01$ & $1 \cdot 71$ \\
\hline Gonadectomized males & $0.43 \pm 0.02 \dagger$ & $0 \cdot 16 \pm 0 \cdot 01 \dagger$ & $2 \cdot 69$ & $0 \cdot 30 \pm 0 \cdot 04^{*}$ & $0 \cdot 19 \pm 0.02^{*}$ & $1 \cdot 59$ \\
\hline
\end{tabular}

${ }^{1}$ Ratio of prolactin receptor short to long mRNA isoforms.

${ }^{*} P<0 \cdot 05$, hepatocytes of rats with $\mathrm{CBDL}$ versus rats without CBDL.

$+P<0 \cdot 05$, hepatocytes of gonadectomized rats versus intact rats.

$\ddagger P<0 \cdot 05$, hepatocytes of male rats versus female rats.

The level of mRNA of both PrlR isoforms increased under CBDL: the long isoform by $2 \cdot 5$-fold and the short isoform by even more, at least 10-fold (Table 2), that is, according to the sensitivity of our method (see Materials and Methods section). In hepatocytes of male and female rats, CBDL was shown to have the opposite effect on the isoform ratio: it increased the ratio of the long to short isoforms (Table 3).

Since hepatocyte functions are altered under CBDL this can cause changes in sex-hormone metabolism and, consequently, levels. We investigated the impact of sex hormones on PrlR mRNA levels under CBDL. In proliferating cholangiocytes PrlR level was not affected by gonadectomy (Fig. 4A), whereas hepatocytes maintain their PrlR expression pattern mainly by sex hormones, as in control animals (Fig. 4B). Surprisingly, gonadectomy was shown to have an effect on the PrlR isoform ratio in neither hepatocytes nor cholangiocytes under CBDL (Tables 2 and 3).

System prolactin level does not affect the parameters of PrlR expression in cholangiocytes

Since sex hormones had no influence on PrlR expression in cholangiocytes of normal and CBDL animals (Fig. 4), we investigated the influence of another positive regulator of PrlR level: prolactin (Baxter \& Zaltsman 1984, Bogorad et al. 2000).

Neither an increase in the systemic prolactin level by graft of pituitaries into kidney capsules nor decrease of prolactin level by administration of bromocriptine significantly changed the intensity of PrlR-positive immunostaining in cholangiocytes under CBDL (Fig. 5). To test the hypothesis of whether autocrine prolactin regulates PrlR expression in rat bile-duct epithelial cells under CBDL we performed RT-PCR to reveal prolactin mRNA. No PCR product was detected in any sample of quiescent or proliferating cholangiocytes (data not shown).

\section{Discussion}

In the present study we have demonstrated that PrlR is expressed in rat cholangiocytes at the level of mRNA as well as of protein. The level of PrlR expression in cholangiocytes of immature rats is much higher than in hepatocytes (Fig. 3B and C), at this stage PrlR expression is sex-independent in both hepatocytes and bile-duct epithelial cells. Further, in contrast to the sex differentiation of PrlR expression in hepatocytes (Sakaguchi et al. 1994), in cholangiocytes the level of PrlR declines but remains sex-independent. Nevertheless, we have shown a low level of PrlR mRNA in cholangiocytes of mature male and female rats (Fig. 4). The level of PrlR protein in cholangiocytes is similar to that in various other tissues: for example pituitary or hypothalamus (Bogorad et al. 2000, Kotok et al. 2000), as well as the level of mRNA (RT-PCR; data not shown). The pattern of PrlR isoforms expression in cholangiocytes is completely opposite to
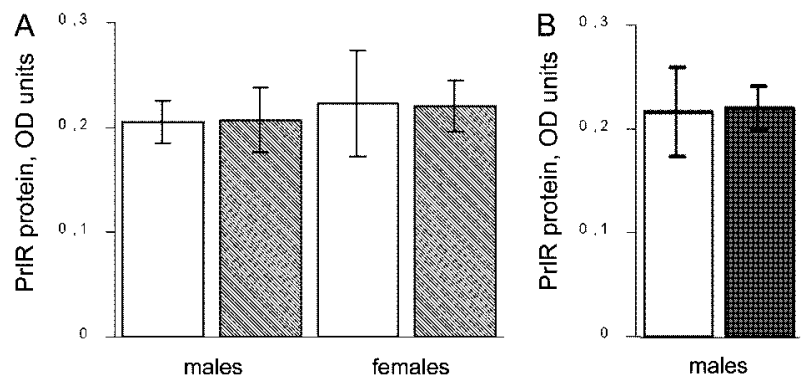

Figure 5 PrlR-positive immunostaining quantified by cytophotometry in cholangiocytes of animals with CBDL after alteration of systemic prolactin level. Expression measured by cytophotometry of immunochemically stained liver sections. Mean OD values \pm S.D are shown. (A) Depletion of pituitary secretion of prolactin: white bars, injection of vehicle; grey bars, injection of bromocriptine. (B) Elevation of prolactin secretion by transplanted pituitaries: white bars, sham-operated animals; black bars, grafts of two pituitaries into kidney capsule. 
hepatocytes (the long form predominates in bile-duct cells; Tables 2 and 3).

The mode of regulation of PrlR total level expression in cholangiocytes has been found to be unusual compared with other types of prolactin target cell: the PrlR level in bile-duct cells does not depend on either sex hormones or prolactin. PrlR gene transcription is controlled by one of three alternative promoters, I, II and III (Hu et al. 1996). In rat hepatocytes, promoter II is the most active; it includes elements responsive to oestrogens, transcription factor AP-1, nuclear hepatocyte factor 4, and STAT proteins (Galsgaard et al. 1999, Hu et al. 1996, Moldrup et al. 1996). Main regulators of PrlR in rat hepatocytes do not influence PrlR expression in cholangiocytes. Thus, all data suggest that the promoter used in cholangiocytes is not that same as the one used in hepatocytes, and hence some other regulatory factors affect PrlR expression in bile-duct epithelial cells.

PrlR expression in cholangiocytes differs from that in hepatocytes not only by total level, but also by mode of alternative splicing. The long isoform of PrlR is the only isoform detected in quiescent cholangiocytes and this profile of expression is not affected by sex hormones (Table 2). On the other hand, in hepatocytes sex hormones regulate the total level of PrlR mRNA and the ratio of PrlR isoforms as well. Female and male sex hormones act on the alternative splicing of PrlR premRNA in rat hepatocytes in a unidirectional manner: they increase the preferential inclusion of the distal exon into mature mRNA (Table 3), although with different efficacies. The effect of oestrogens on alternative splicing resulting in preferential usage of the distal exon was demonstrated for growth hormone receptor pre-mRNA in mouse hepatocytes (Talamantes \& Ortiz 2002) and for PrlR pre-mRNA in rat hepatocytes (Sakaguchi et al. 1994). The level of long PrlR isoforms in normal cholangiocytes is almost equal to that found in hepatocytes of male and female rats (Tables 2 and 3). Hence, activation by prolactin of JAK/STAT and some other cascades can be expected from the rather pronounced level in bile-duct cells of normal animals.

We have detected elevated PrlR levels in actively proliferating cholangiocytes of immature rats. Thus prolactin may participate in the regulation of bile ducts of developing liver. We have also shown that experimental stimulation of cholangiocytes proliferation by CBDL in mature rats leads to a dramatic increase of PrlR. The PrlR level in rat hepatocytes is not significantly affected under the same conditions (Fig. 4). PrlRs are not the only receptors whose level increases in proliferating cholangiocytes under obstructive cholestasis: it has been found that the same trend is a characteristic feature of receptors for secretin (Alpini et al. 1994b) and oestrogen (Alvaro et al. 2000a). Thus, the responsiveness of cholangiocytes to various regulatory factors including prolactin is enhanced under obstructive cholestasis.
We have also shown that CBDL is associated with the shift in ratio of PrlR isoforms in rat cholangiocytes as well as in hepatocytes. While in hepatocytes it increases the proportion of the long isoform (Table 3), in cholangiocytes it has the opposite effect: CBDL in these cells causes the appearance of the short isoform of PrlR (Table 2).

The increased cholangiocyte susceptibility to prolactin may play a role in the direct regulation of bile-duct cell function. We have shown previously that prolactin participates in stimulation of cholangiocyte proliferation after CBDL (Orlova et al. 1999). Taking into account that the level of the long isoform increases under CBDL, this effect seems to be mediated by activation of the JAK/STAT cascade and some other kinases. Similar cascades are activated by interleukin-6 and insulin-like growth factor, which have been shown to stimulate cholangiocyte proliferation (Alvaro et al. 2000b).

Prolactin could be considered as a factor participating in the maintainance of normal bile-duct structure and the polarity of cholangiocytes. The intercellular junctions are shown to be dramatically altered under obstructive cholestasis; for example, the level of connexins decreases (Fallon et al. 1995). Connexins 32 and 43 are the main proteins of gap junctions of hepatocytes and cholangiocytes respectively (Bode et al. 2002, Fallon et al. 1995). Prolactin has been shown to increase connexin levels for example, connexin 32 in mammary gland (Miyoshi et al. 2001) and connexin 43 in pancreas islets (Collares-Buzato et al. 2001). Our preliminary data on connexin expression in cholangiocytes and hepatocytes of investigated groups are in agreement with this suggestion, although further experiments are essential. Another protein, which could be potentially regulated by prolactin in cholangiocytes, is apical bile salt transporter. This protein relates to prolactin-regulated NTCP $\left(\mathrm{Na}^{+} /\right.$taurocholate cotransporting polypeptide; Lui et al. 1995). Preliminary experiments have shown some correlation between apical bile salt transporter and PrlR level in rat cholangiocytes under normal and cholestatic conditions, these data are also under investigation in our laboratory.

In summary, this study is the first demonstration of PrlR expression in rat cholangiocytes. The long isoform of PrlR is predominant in these cells. It is noteworthy that this profile of PrlR expression is typical for most tissues but not for hepatocytes. Due to the very low level of the PrlR short isoform, its total level in cholangiocytes is lower than in hepatocytes. Surprisingly, PrlR expression in cholangiocytes does not depend on sex hormones or prolactin, in contrast to many other tissues. Both PrlR isoforms are dramatically induced by CBDL in cholangiocytes but not in hepatocytes. Thus, the different mode of expression of PrlR isoforms and their differential regulation in the various types of cells in liver should be considered as a possible mechanism for enhancing of prolactin signalling specificity in this tissue under normal and pathological conditions. 


\section{Acknowledgements}

We thank Dr Vincent Goffin and Professor Paul Kelly (INSERM, France) for their kind gift of U5 antibodies as well as for helpful discussion of manuscript. We are grateful to Dr Antonio Benedetti and Dr Luca Marucci (University of Ascona, Ascona, Italy) for their advice on isolation of intrahepatic bile-duct units and to Dr Olga Petratshuk (Moscow State University, Moscow, Russia) for her assistance with immunohistochemistry and microphotography of immature rat liver tissue. The authors declare that there is no conflict of interest that would prejudice the impartiality of this scientific work.

\section{References}

Alpini G, Lenzi R, Sarkozi L \& Tavoloni N 1988 Biliary physiology in rats with bile ductular cell hyperplasia. Evidence for a secretory function of proliferated bile ductules. Journal of Clinical Investigation 81 569-578.

Alpini G, Lenzi R, Zhai WR, Slott PA, Liu MH, Sarkozi L \& Tavoloni N 1989 Bile secretory function of intrahepatic biliary epithelium in the rat. American Journal of Physiology Gastrointestinal and Liver Physiology 257 G124-G133.

Alpini G, Phillips JO, Vroman B \& LaRusso NF 1994a Recent advances in the isolation of liver cells. Hepatology 20 494-514

Alpini G, Ulrich CD 2nd, Phillips JO, Pham LD, Miller LJ \& LaRusso NF $1994 b$ Up-regulation of secretin receptor gene expression in rat cholangiocytes after bile duct ligation. American Journal of Physiology Gastrointestinal and Liver Physiology 266 G922-G928.

Alvaro D, Alpini G, Onori P, Perego L, Svegliati Baroni G, Franchitto A, Baiocchi L, Glaser SS, Le Sage G, Folli F \& Gaudio E 2000a Estrogens stimulate proliferation of intrahepatic biliary epithelium in rats. Gastroenterology 119 1681-1691.

Alvaro D, Gigliozzi A \& Attili AF $2000 b$ Regulation and deregrulation of cholangiocyte proliferation. Journal of Hepatology 33 333-340.

Baxter RC \& Zaltsman Z 1984 Induction of hepatic receptors for growth hormone $(\mathrm{GH})$ and prolactin by $\mathrm{GH}$ infusion is sex independent. Endocrinology 115 2009-2014.

Bode HP, Wang L, Cassio D, Leite MF, St-Pierre MV, Hirata K, Okazaki K, Sears ML, Meda P, Nathanson MH \& Dufour MH 2002 Expression and regulation of gap junctions in rat cholangiocytes. Hepatology 36 631-640.

Bogorad RL, Kotok T, Smirnov AN, Turovetskii VM \& Smirnova OV 2000 Expression of prolactin receptors in rat reproductive tissues during periovulatory prolactin imbalance. Bulletin of Experimental Biology and Medicine 129 608-611.

Bogorad RL, Smyslova VS, Smirnov AN, Rubtsov PM \& Smirnova OV 2002 The ratio of prolactin receptor isoforms in rat hepatocytes: the effect of obstructive cholestasis. Molecular Biology (Moscow) 36 71-73.

Bogorad RL, Zenkova TJ, Rubtsov PM \& Smirnova OV 2004 The influence of obstructive cholestasis and sex hormones on the ratio of mRNA of two alternative prolactin receptor isoforms in rat hepatocytes. Biochemistry (Moscow) 69 1114-1122.

Bole-Feysot C, Goffln V, Edery M, Binart N \& Kelly PA 1998 Prolactin and its receptor: actions, signal transduction pathways and phenotypes observed in prolactin receptor knockout mice. Endocrine Review 19 225-268.

Chomczynski P \& Sacchi N 1987 Single-step method of RNA isolation by acid guanidinium thiocyanate-phenol-chloroform extraction. Analitical Biochemistry 162 156-159.
Collares-Buzato CB, Leite AR \& Boschero AC 2001 Modulation of gap and adherens junctional proteins in cultured neonatal pancreatic islets. Pancreas 23 177-185.

Das R \& Vonderhaar BK 1995 Transduction of prolactin's growth signal through both long and short forms of the PRL receptors. Molecular Endocrinology 9 1750-1759.

Duan WR, Parmer TG, Albarracin CT, Zhong L \& Gibori G 1997 PRAP, a prolactin receptor associated protein: its gene expression and regulation in the corpus luteum. Endocrinology 138 3216-3221.

Fallon MB, Nathanson MH, Mennon A, Saez JC, Burgstahler AD \& Anderson JM 1995 Altered expression and function of hepatocyte gap junctions after common bile duct ligation in the rat. American Journal of Physiology Cell Physiology 268 C1186-C1194.

Galsgaard ED, Nielsen JH \& Moldrup A 1999 Regulation of prolactin receptor (PRLR) gene expression in insulin-producing cells. Prolactin and growth hormone activate one of the rat prlr gene promoters via STAT5a and STAT5b. Journal of Biological Chemistry 274 18686-18692.

Garcia MC, Lopez M, Gualillo O, Seoane LM, Dieguez C \& Senaris RM 2003 Hypothalamic levels of NPY, MCH, and prepro-orexin mRNA during pregnancy and lactation in the rat: role of prolactin. FASEB Journal 17 1392-1400.

Horseman ND, Zhao W, Montecino-Rodriguez E, Tanaka M, Nakashima K, Engle SJ, Smith F, Markoff E \& Dorshkind K 1997 Defective mammopoiesis, but normal hematopoiesis, in mice with a targeted disruption of the prolactin gene. EMBO Journal 16 6926-6935.

Hu ZZ, Li Z \& Dufau ML 1996 Multiple and tissue-specific promoter control of gonadial and non-gonadial prolactin receptor gene expression. Journal of Biological Chemistry 271 10242-10246.

Jolicoeur C, Boutin JM, Okamura H, Raguet S, Djane J \& Kelly PA 1989 Multiple regulation of prolactin receptor gene expression in rat liver. Molecular Endocrinology 3 895-900.

Kotok T, Bogorad RL, Smirnov AN, Turovetskii VM \& Smirnova OV 2000 The effect of periovulatory imbalance of prolactin on the expression of prolactin receptors in rat ovary cells. Russian Journal of Developmental Biology 31 117-123.

Liu Y, Hyde JF \& Vore M 1992 Prolactin regulates maternal bile secretory function post partum. Journal of Pharmacology and Experimental Therapy 261 560-566.

Liu Y, Ganguly T, Hyde JF \& Vore M 1995 Prolactin increases mRNA encoding $\mathrm{Na}+-\mathrm{TC}$ co-transport polypeptide and hepatic Na+-TC co-transport. American Journal of Physiology Gastrointestinal and Liver Physiology 268 G11-G17.

Mennone A, Alvaro D, Cho W \& Boyer JL 1995 Isolation of small polarized bile duct units. PNAS 92 6527-6231.

Miyoshi K, Shillingford JM, Smith GH, Grimm SL, Wagner KU, Oka T, Rosen JM, Robinson GW \& Hennighausen L 2001 Signal transducer and activator of transcription (Stat) 5 controls the proliferation and differentiation of mammary alveolar epithelium. Journal of Cell Biology 155 531-542.

Moldrup A, Ormandy C, Nagano M, Murthy K, Banville D, Tronche F \& Kelly PA 1996 promoter usage in prolactin receptor gene expression: hepatocyte nuclear factor 4 binds to and activates the promoter preferentially active in the liver. Molecular Endocrinology $10661-671$.

Nagano M \& Kelly P 1994 Tissue distribution and regulation of rat prolactin receptor gene expression. Quantitative analysis by polimerase chain reaction. Journal of Biological Chemistry $26913337-13345$.

Nikelainen P, Peltoketo H, Vihko R \& Vihko P 1998 Expression cloning of a novel estrogenic mouse 17-hydroxysteroid dehydrogenase/17-ketosteroid reductase (m17 HSD7), previously described as a prolactin receptor-associated protein (PRAP) in rat. Molecular Endocrinology 12 1048-1059.

Orlova AN, Smirnov AN \& Smirnova OV 1999 [The role of prolactin in the functional regulation of liver cells after the 
common bile duct ligation]. Bulletin of Experimental Biology and Medicine 127 573-575 [in Russian].

Ormandy CJ, Binart N \& Kelly PA 1997 Mammary gland development in prolactin receptor knockout mice. Journal of Mammary Gland Biology and Neoplasia 2 355-364.

Perrot-Applanat M, Gualillo O, Pezet A, Vincent V, Edery M \& Kelly PA 1997 Dominant negative and cooperative effects of mutant forms of prolactin receptor. Molecular Endocrinology 11 1020-1032.

Picoletti R, Bendinelli P \& Maroni P 1997 Signal transduction pathway of prolactin in rat liver. Molecular and Cellular Endocrinology 135 169-177.

Sakaguchi K, Ohkubo T, Sugiyama T, Tanaka M, Ushiro H \& Nakashima K 1994 Differential regulation of prolactin receptor mRNA expression in rat liver and kidney by testosterone and oestradiol. Journal of Endocrinology 143 383-392.
Smirnova O, Petraschuk O \& Kelly P 1994 Immunohystochemical localization of prolactin receptor in rat liver cells: I. Dependence on sex and sex steroids. Molecular and Cellular Endocrinology 105 77-81.

Smirnova OV, Petrashchuk OM \& Smirnov AN 1998 [Induction of expression of prolactin receptors in cholangiocytes of male and female rats after ligation of the common bile duct]. Bulletin of Experimental Biology and Medicine 125 66-70 [in Russian].

Talamantes F \& Ortiz R 2002 Structure and regulation of expression of the mouse GH receptor. Journal of Endocrinology 175 55-59.

Received in final form 30 September 2005

Accepted 13 October 2005

Made available online as an Accepted Preprint 18 November 2005 